BNL-96705-2011

\title{
Temporary Cementitious Sealers in Enhanced Geothermal Systems
}

\author{
Phase I
}

FYs 2009-2011

\section{Toshifumi Sugama, Tatiana Pyatina, Thomas Butcher, Lance Brothers, and Daniel Bour}

December 2011

\author{
Sustainable Energy Technologies Department \\ Brookhaven National Laboratory
}

\section{U.S. Department of Energy USDOE - Office of Energy Efficiency \& Renewable Energy}

\footnotetext{
Notice: This manuscript has been authored by employees of Brookhaven Science Associates, LLC under Contract No. DE-AC02-98CH10886 with the U.S. Department of Energy. The publisher by accepting the manuscript for publication acknowledges that the United States Government retains a non-exclusive, paid-up, irrevocable, world-wide license to publish or reproduce the published form of this manuscript, or allow others to do so, for United States Government purposes.
} 


\section{DISCLAIMER}

This report was prepared as an account of work sponsored by an agency of the United States Government. Neither the United States Government nor any agency thereof, nor any of their employees, nor any of their contractors, subcontractors, or their employees, makes any warranty, express or implied, or assumes any legal liability or responsibility for the accuracy, completeness, or any third party's use or the results of such use of any information, apparatus, product, or process disclosed, or represents that its use would not infringe privately owned rights. Reference herein to any specific commercial product, process, or service by trade name, trademark, manufacturer, or otherwise, does not necessarily constitute or imply its endorsement, recommendation, or favoring by the United States Government or any agency thereof or its contractors or subcontractors. The views and opinions of authors expressed herein do not necessarily state or reflect those of the United States Government or any agency thereof. 


\title{
Temporary Cementitious Sealers in Enhanced Geothermal Systems
}

\author{
Phase I \\ FYs 2009-2011 \\ Final Report \\ Prepared for \\ The U.S. Department of Energy \\ Energy Efficiency and Renewable Energy \\ Geothermal Technologies Program \\ 1000 Independence Avenue SW \\ Washington, D.C. 20585 \\ Prepared by \\ Toshifumi Sugama, Tatiana Pyatina, and Thomas Butcher \\ Sustainable Energy Technologies Department \\ Brookhaven National Laboratory \\ Upton, NY 11973-5000 \\ Lance Brothers \\ Halliburton \\ 2600 S. $2^{\text {nd }}$ Street \\ P.O. Drawer 1431 \\ Duncan, OK 73536-0442 \\ Daniel Bour \\ AltaRock Energy, Inc. \\ 7900 E. Green Lake Drive N., Suite 202 \\ Seattle, WA 98103-4818
}

December 2011

Notice: This manuscript has been authored by an employee of Brookhaven Science Associates, LLC under Contract No. DE-AC02-98CH 10886 with the U.S.

Department of Energy. The publisher by accepting the manuscript for publication acknowledges that the United States Government retains a non-exclusive, paid-up, irrevocable, world-wide license to publish or reproduce the published form of this manuscript, or allow others to do so, for the United States Government purposes. 


\section{TABLE OF CONTENTS}

Exclusive Summary $\frac{\text { Pages }}{4}$

$\begin{array}{ll}\text { Introduction } & 7\end{array}$

$\begin{array}{ll}\text { Experimental Procedure } & 10\end{array}$

$\begin{array}{ll}\text { Measurements } & 11\end{array}$

$\begin{array}{ll}\text { Results and Discussion } & 12\end{array}$

Task 1. Establish the basic formulation of the temporary sealing materials $\quad 12$

$\begin{array}{ll}\text { 1.1 Initial and final setting times } & 12\end{array}$

1.2 Sodium carboxymethyl cellulose (CMC) additive as promoter of self-degradation

1.3 Thermal decomposition behaviors of CMC in AACM 16

$\begin{array}{ll}1.4 \text { Compressive strength and porosity } & 18\end{array}$

1.4.1 Slag (S)/Class F fly ash (F) system $\quad 18$

1.4.2 Slag (S)/Class C fly ash (C) system $\quad 21$

$\begin{array}{ll}\text { 1.5 Phase identification } & 22\end{array}$

1.5.1 Slag (S)/Class F fly ash (F) system 22

1.5.2 Slag (S)/Class C fly ash (C) system 29

Task 2. Characterization of the sealing materials developed 31

$\begin{array}{ll}2.1 \text { Self-degradation } & 31\end{array}$

2.1.1 Effect of CMC on self-degradation 31

2.1.2 Hydrothermal reaction products affecting self-degradation $\quad 34$

2.1.3 Self-degradation mechanism 36

2.1.4 Efficacy of sodium silicate in facilitating self-degradation 
Under a high hydrothermal pressure of $1000 \mathrm{psi} \quad 40$

2.1.5 Effect of CMC content on self-degradation of sodium silicate-rich sealers

Task 3. Prepare interim report

Task 4. Modify the formulation developed to assure the expansion/swelling Properties

4.1 Expansion

4.2 Compressive strength

4.3 Phase identification and SEM exploration

\subsection{Self-degradation}

Task 5. Technology transfer to geothermal industries

Conclusions

Future Directions

References 


\section{Exclusive Summary}

Unlike conventional hydrothermal geothermal technology that utilizes hot water as the energy conversion resources tapped from natural hydrothermal reservoir located at $\sim 10$ $\mathrm{km}$ below the ground surface, Enhanced Geothermal System (EGS) must create a hydrothermal reservoir in a hot rock stratum at temperatures $\geq 200^{\circ} \mathrm{C}$, present in $\sim 5 \mathrm{~km}$ deep underground by employing hydraulic fracturing. This is the process of initiating and propagating a fracture as well as opening pre-existing fractures in a rock layer. In this operation, a considerable attention is paid to the pre-existing fractures and pressuregenerated ones made in the underground foundation during drilling and logging. These fractures in terms of lost circulation zones often cause the wastage of a substantial amount of the circulated water-based drilling fluid or mud. Thus, such lost circulation zones must be plugged by sealing materials, so that the drilling operation can resume and continue. Next, one important consideration is the fact that the sealers must be disintegrated by highly pressured water to reopen the plugged fractures and to promote the propagation of reopened fractures.

In response to this need, the objective of this phase I project in FYs 2009-2011 was to develop temporary cementitious fracture sealing materials possessing self-degradable properties generating when $\geq 200^{\circ} \mathrm{C}$-heated sealers came in contact with water. At BNL, we formulated two types of non-Portland cementitious systems using inexpensive industrial by-products with pozzolanic properties, such as granulated blast-furnace slag from the steel industries, and fly ashes from coal-combustion power plants. These byproducts were activated by sodium silicate to initiate their pozzolanic reactions, and to create a cemetitious structure. One developed system was sodium silicate alkali-activated slag/Class C fly ash (AASC); the other was sodium silicate alkali-activated slag/Class F fly ash (AASF) as the binder of temporary sealers. Two specific additives without sodium silicate as alkaline additive were developed in this project: One additive was the sodium carboxymethyl cellulose (CMC) as self-degradation promoting additive; the other was the hard-burned magnesium oxide $(\mathrm{MgO})$ made from calcinating at $1,000-1,500^{\circ} \mathrm{C}$ as an expansive additive. The AASC and AASF cementitious sealers made by incorporating an appropriate amount of these additives met the following six criteria: 1) One dry mix component product; 2) plastic viscosity, 20 to $70 \mathrm{cp}$ at $300 \mathrm{rpm}$; 3) maintenance of pumpability for at least 1 hour at $85^{\circ} \mathrm{C}$;4) compressive strength $>2000 \mathrm{psi}$; 5) selfdegradable by injection with water at a certain pressure; and 6) expandable and swelling properties; $\geq 0.5 \%$ of total volume of the sealer.

The total four AASC and AASF cement systems representating 40/60 and 20/80 slag/Class C fly ash ratios, and $80 / 20$ and $60 / 40$ slag/Class F fly ash ratios were selected as candidates for temporary sealers displaying the property of self-degradation. After mixing these cement systems with water and autoclaving them at $200^{\circ} \mathrm{C}$, we identified three crystalline phases, calcium silicate hydrate (l) [C-S-H (l)], and aluminumsubstituted and non-substituted $1.1 \mathrm{~nm}$ tobermorite crystal phases, as well as geopolymer as amorphous phase, as hydrothermal reaction products responsible for the development of a compressive strength $>2000 \mathrm{psi}$. Sodium hydroxide derived from the hydrolysis of the sodium silicate activator not only initiated the pozzolanic reaction of the slag and fly ashes, but also played an important role in generating in-situ exothermic heat that 
significantly contributed to promoting the self-degradation of these cementitious sealers. The source of this exothermic heat was the interactions between sodium hydroxide and gaseous $\mathrm{CO}_{2}$ - and $\mathrm{CH}_{3} \mathrm{COOH}$ - by-products generated from the thermal decomposition of $\mathrm{CMC}$ additive at $\geq 200^{\circ} \mathrm{C}$ in an aqueous medium. Thus, the magnitude of this selfdegradation depended on the exothermic temperature evolved in the sealer; a higher temperature led to a more severe disintegration of sealer. In contrast, the excessive formation of the geopolymer phase due to more incorporation of Class $\mathrm{F}$ fly ash into this cementitious system prevented its ability to self-degrade; namely, no self-degradation occurred. This geopolymer was formed by hydrothermal reactions between the sodium hydroxide from sodium silicate and the mullite in Class F fly ash. Thus, the major reason why geopolymer-based cementitious sealers did not degrade after heated sealers came in contact with water was their lack of free sodium hydroxide.

Other factor affecting the magnitude of self-degradation of the sealers was the hydrothermal pressure adapted during their autoclave-curing processes; namely, under a high pressure, more sodium silicate had to be incorporated to promote self-degradation because the high reactivity of sodium silicate with the slag and fly ashes resulting from a high pressure led to a loss in free sodium hydroxide. For instance, at 1000 psi pressure, the effective amount of sodium silicate in expediting the self-degradation was $9.7 \%$ by total amount of dry cement mixture, compared with its $4.1 \%$ at 300 psi.

CMC had two effects; it promoted self-degradation, and also retarded setting, thereby delaying the initial setting time of cement slurries. Thus, adding an extra amount of CMC had controlled a rapid setting behavior of cement slurry made with $9.7 \%$ sodium silicate. However, with $1.5 \% \mathrm{CMC}$, its effectiveness in aiding self-degradation almost was the same as that of $0.7 \%$ of CMC.

We identified hard-burned magnesium oxide $(\mathrm{MgO})$ as a suitable expansive additive for improving the plugging performance of cementitious sealers. $\mathrm{MgO}$ extended the volumetric expansion of sealers during their exposure to a hydrothermal environment at $200^{\circ} \mathrm{C}$ under pressures ranging from 300 to $1500 \mathrm{psi}$. The most effective content of $\mathrm{MgO}$ in minimizing cracks, and eliminating their generation was $2.0 \mathrm{wt} \%$, which gave a moderate expansion of $\geq 0.5 \%$. The compressive strength of $2.0 \mathrm{wt} \% \mathrm{MgO}$ specimens made under a pressure of $300 \mathrm{psi}$ rose $~ 1.7$-fold to $4816 \mathrm{psi}$ with an increasing pressure to $1500 \mathrm{psi}$. The in-situ growth of brucite crystal formed by the hydrothermal hydration of $\mathrm{MgO}$ was responsible for such expansion of the sealers. Thus, increasing the pressure seems to suppress and control the growth rate of brucite crystal in response to a lower extension of expansion.

This BNL-developed temporary cementitiuos sealer technology was transferred to two geothermal industries, Halliburton and Alta Rock Energy, Inc. for their own technical evaluations. The outcome from evaluations will provide us with information on the potential feasibility of applying this technology, and the needs of further technical improvement. 
When a field-applicable temporary cementitious sealer possessing all the material criteria is formulated, it will eliminate three critical issues that must be solved for reducing sealing and drilling operation costs in EGS wells: One issue involves lost circulation problems, where a great deal of circulated drilling fluid is lost in pre-existing fractures and new ones created by drilling; the second problem centers on the emplacement of additional isolated liners covering the fracture inlets; and the third is the managed pressure drilling operation. Thus, these temporary sealers will benefit greatly the reservoir-creating processes in EGS wells. Eliminating these three problems will entail substantial decrease both in capital investments and expenditures during sealing and drilling operations. 


\section{Introduction}

A critical operation in assembling and constructing Enhanced Geothermal Systems (EGSs) is the creation of a hydrothermal reservoir in a granite rock stratum at temperatures $\geq 200^{\circ} \mathrm{C}$, located at $\sim 3-10 \mathrm{~km}$ below the ground surface. In this operation, water is pumped down from injection well to stimulate the hot rock stratum. This hydraulic stimulation in terms of hydro-fracturing initiates the opening of existing fractures. Also, multi-injection wells are required to create a desirable reservoir of a permeable fracture flow network. After forming the reservoir, a production well is installed within the fracture's network.

During such construction of wellbores, operators pay considerable attention to the preexisting fractures and the pressure-generated ones made in the underground foundation during drilling and logging. These fractures in terms of lost circulation zones often cause the wastage of a substantial amount of the circulated water-based drilling fluid or mud. To deal with this problem, operators must seal or plug the lost circulation zones with the proper materials to avoid depleting the drilling fluid and mud. Once this problem is resolved, the drilling operation can resume and continue until the wellbore structure is completed. Thereafter, the hydraulic-stimulation process begins. Next, the inevitable concern is the fact that all sealing materials used to plug the fractures in hydrothermal reservoir's rock stratum must be disrupted by water under a certain pressure to reopen the sealed fractures, and so promote the propagation of reopened fractures.

In response to this need, the objective of this phase I project in a period of FYs 20092011 is to develop temporary cementitious fracture sealing materials with self-degradable properties. The ideal sealer's self-degradation must take place when sealers at temperatures of $\geq 200^{\circ} \mathrm{C}$ come in contact with water. If successful, outcome of our research will reduce the total costs of the sealing and multi-fracture drilling operations, and lower the overall expense of raw materials, while eliminating the following three critical problems: 1) Lost of circulation; 2) the need for additional isolation liners; and, 3) the managed pressure drilling. Unlike a conventional R\&D project designing tough, durable cementitious materials, our current project aimed at developing a temporary cementitious sealer is required that sealer exhibits good mechanical-and sealing behaviors, while self-degrading under a combination of high temperature and water injection. Thus, the challenge we faced was to find ways how to disintegrate a hard hydraulic cementitious material in hot EGS wells by injecting water without any added chemical reagents. Additionally, our project's goal involved transferring the BNLdeveloped sealer technology to the geothermal drilling and service industries.

In our previous DOE project aimed at developing cost-effective acid-resistant cements for the conventional geothermal wells, researchers at Brookhaven National Laboratory (BNL) formulated alkali-activated cementitious materials (AACMs) that resisted acid much better than did the OPCs $[1,2]$. The AACMs were prepared hydrothermally using two major components: One was inexpensive industrial by-products with pozzolanic properties, such as the slag from steel industries and the fly ashes from coal-combustion power plants; the other was sodium silicate along with various mol. ratios of $\mathrm{Na}_{2} \mathrm{O} / \mathrm{SiO}_{2}$ as the alkali activators to initiate the pozzolanic reactions. Our assessment of these by- 
product resources strongly highlighted the beneficial environmental effects of their usage. According to the U.S. Geological Survey, in 2000, U.S steel industries generated 8.9 million tons of slag as wastes and by-products [3], and in 2009, 5.7 million tons of fly ash by-products were yielded from U.S. coal combustion power plants [4]. Of these amounts, 5.1 million tons of slag and 2.2 million tons of fly ash were recycled into industrial products. Thus, this abundant resource of these by-products as the starting materials of our cementitious sealer assures their local availability across the U.S.A.

From the standpoint of assuring the self-degradation of cementitious materials, the biodegradable biopolymers including the starch, cellulose acetate, gelatin, and poly $\mathrm{L}_{\mathrm{L}}$ lactic acid) in the form of powder, microsphere, and fiber, are currently used as additives, which promote the partial biological degradation of biocompatible bone cements [5-8]. When these additives in bone cements came in contact with body fluids, they disintegrate, so creating high porosity therein, and assuring the development of interconnective channels for the bone tissue's growth and facilitating the resorption of such cements. Our particular interest in biopolymers was their intriguing mechanism of thermal degradation. The cellulose and cellulose-related compounds are degraded thermally in air and water at temperatures around $200^{\circ} \mathrm{C}$; yielding acetic acid as byproducts [9-11]. This information inspired us to investigate the potential of cellulose compounds as thermal degradable additives to promote the self-degradation of temporary cementitious sealing materials at temperatures $\geq 200^{\circ} \mathrm{C}$ after the water has penetrated through the sealer.

Based upon this concept, our focus in this study centered on formulating AACMs, in particular, slag/Class $\mathrm{C}$ and $\mathrm{F}$ fly ashes combined system, as the binder in temporary sealing material, and investigating the ability of sodium carboxymethyl cellulose (CMC) as thermal degradable additive to promote the disintegration of AACM-based sealer. $\mathrm{CMC}$ and cellulose-related compounds were not new materials in the drilling industries. These compounds frequently are used as additives in water-based drilling mud to reduce fluid loss in mud, to confer water-holding properties on mud, and to assure its appropriate rheology at elevated temperature [12-14]. In addition, the AACM systems do not incorporate any Ordinary Portland Cement (OPC) that emits 0.9 metric ton $\mathrm{CO}_{2}$ gas [15] and a great deal of mercury [16] during the manufacture of every ton of OPC; this greatly underscores the value of our cementitious sealer in eliminating carbon footprints.

Another important property in designing sealing materials is to assure an expansion in their volume upon exposure to hydrothermal environments at $\geq 200^{\circ} \mathrm{C}$. Such a volume expansion of sealers emplaced in the fractures improves their plugging performance by enhancing their adherence to the inner surface of fracture: This ensures that the sealers have adequate stability and reliability without their being washed out and removed by a locally disbanded sealer during further drilling operations. The commonest ways to increase the volume of cementitious materials is to utilize the in-situ growth of the crystalline hydration products formed in the cementitious bodies. Among those products, the sulfoaluminate (ettringite )[17,18]-, and $\mathrm{Ca}$ and $\mathrm{Mg}$ oxides[19-23]-based hydration products are well recognized as satisfactorily expandable ones. The representative crystalline phase of first hydration product is ettringite, $3 \mathrm{CaO} \cdot \mathrm{Al}_{2} \mathrm{O}_{3} \cdot \mathrm{CaSO}_{4} \cdot 32 \mathrm{H}_{2} \mathrm{O}$, 
containing a large volume of water, and it is formed by mixing five starting materials; Portland cement, anhydrous hauyne $\left(3 \mathrm{CaO} .3 \mathrm{Al}_{2} \mathrm{O}_{3} \cdot \mathrm{CaSO}_{4}\right)$, gypsum $\left(\mathrm{CaSO}_{4}\right)$, quick lime $(\mathrm{CaO})$, and water [24]. However, ettringite displays two major drawbacks in a high temperature environment: The first is a delay in its formation at a heating temperature > $70^{\circ} \mathrm{C}$ [25-28]; and, the second is its hydrothermal decomposition at temperature $>170^{\circ} \mathrm{C}$ [29]. Thus, this volume expansion technology was inapplicable to our sealer.

When the $\mathrm{CaO}$ and $\mathrm{MgO}$ expansive additives embedded in OPC neat paste are autoclaved, the additive's hydration initiated promptly in an alkaline environment created by the hydrolysis of OPC, reflecting the conversion of the $\mathrm{Ca}$ - and $\mathrm{Mg}$-oxides into crystalline $\mathrm{Ca}$ and $\mathrm{Mg}$ hydroxides. Afterward, the pressure generated by their in-situ growth extends the expansion and swelling of hydrothermally cured OPC. However, in our previous study on the phase identification in autoclaved sodium silicate-activated slag/Class $\mathrm{C}$ fly ash cementitious material [30], we found that all free lime, $\mathrm{CaO}$, present in Class $\mathrm{C}$ fly ash hydrothermally reacted with the slag to form crystalline calcium silicate hydrates, such as calcium silicate hydrate (l) and $1.1 \mathrm{~nm}$ tobermorite. We did not detect $\mathrm{Ca}(\mathrm{OH})_{2}$-related crystal phase, which aids in expanding the autoclaved cementitious material. This finding seemingly suggested that the $\mathrm{CaO}$ expansive additive might not be useable in the autoclaved sodium silicate-activated slag/Class $\mathrm{C}$ fly ash system because of its reactivity with silicate species, rather than forming $\mathrm{Ca}(\mathrm{OH})_{2}$. Thus, our interest focused on investigating the usefulness of dead-burned $\mathrm{MgO}$ as an expansive additive for AACMs.

The sealers to be developed were required to meet all the following nine material criteria: 1) One dry mix component product; 2) plastic viscosity, 20 to $70 \mathrm{cp}$ at $300 \mathrm{rpm}$; 3) be suitable for conventional cement squeezing technology; 4) maintenance of pumpability for at least 1 hour at $85^{\circ} \mathrm{C} ; 5$ ) compressive strength $>2000$ psi; 6) be self-degradable by injection with water under a certain pressure; 7) expandable and swelling properties $\geq 0.5$ $\%$ of total volume of sealer; 8 ) excellent penetration through fractures of $\sim 0.04$ in. wide spacing; and 9) anti-filtration properties.

To achieve this Phase I project goal, we directed our emphasis towards completing the following six major tasks in FY2009-2011:

Task 1. Establish the basic formulation of temporary sealing materials;

Task 2. Characterization of sealing materials developed;

Task 3. Prepare interim report;

Task 4. Modify the formulation developed to assure the expansion/swelling properties;

Task 5. Technology transfer to geothermal industries;

Task 6. Prepare phase I final report.

In tasks 1 and 2, the studies included three subjects: The first subject was to optimize the formula for blending the CMC-containing alkali-activated slag/Class $\mathrm{C}$ and /Class F fly ash dry components, using data on its setting time, compressive strength, and identification of the crystalline phases responsible for strengthening the cementitious sealers; the second one was to collect information on the thermal decomposition of CMC 
additive and the chemistry of decomposed $\mathrm{CMC}$; and the final one was to visualize the self-degradation of the AACM sealer and to determine in-situ exothermic energy evolved in the sealers while water penetrated through them. The integration of all information described above was directed toward clearly understanding the mechanism of selfdegradation.

In task 4, the study centered on two major R\&D efforts: First, we explored the compatibility of $\mathrm{MgO}$ with the self-degradable AACMs; second, we detailed the effectiveness of $\mathrm{MgO}$ in extending the rate of expansion of AACMs under pressures ranging from 300 to 1500 psi. The former work involved measuring the compressive strength of $200^{\circ} \mathrm{C}$-autoclaved cements by varying the content of $\mathrm{MgO}$ under four different pressures, 300, 600, 1000, and 1500 psi. In addition, we assessed whether MgOmodified AACMs still can self-degrade. The second effort encompassed measuring the rate of expansion, identifying the hydrothermally hydrated reaction products, and exploring the development of microstructure in the expanded cement.

\section{Experimental Procedure}

Two industrial by-products with pozzolanic properties, granulated blast-furnace slag under trade name "New Cem," and Class C and F fly ashes were used as the hydraulic pozzolana cement. The slag was supplied from Lafarge North America, and fly ashes were obtained from Boral Material Technologies, Inc. Table 1 lists their chemical constitutions. A sodium silicate granular powder under trade name "Metos Bead 2048," supplied by The PQ Corporation was used as the alkali activator of these pozzolana cements; its chemical composition was $50.5 \mathrm{~mol}$. wt $\% \mathrm{Na}_{2} \mathrm{O}$ and $46.6 \mathrm{~mol}$. wt $\% \mathrm{SiO}_{2}$. The formula of the dry pozzolana cements employed in this test had slag/Class $\mathrm{C}$ and $/ \mathrm{F}$ fly ash ratios of $100 / 0,80 / 20,60 / 40,40 / 60$, and $20 / 80$ by weight. Sodium silicate powder as alkali activator, and its $4.1,6.8$, and $9.7 \%$ by the total weight of pozzolana cement was added to prepare the dry mix cementitious reactant. Commercial Class G well cement was used as a control.

Table 1. Chemical composition of Ground Granulated Blastfurnace Slag, and Class C and $F$ fly ashes.

\begin{tabular}{|c|c|c|c|c|c|c|c|c|c|c|}
\hline & $\begin{array}{l}\mathrm{CaO}, \\
\mathrm{wt} \%\end{array}$ & $\begin{array}{l}\mathrm{SiO}_{2}, \\
\mathrm{wt} \%\end{array}$ & $\begin{array}{l}\mathrm{Al}_{2} \mathrm{O}_{3}, \\
\mathrm{wt} \%\end{array}$ & $\begin{array}{l}\text { MgO, } \\
\text { wt \% }\end{array}$ & $\begin{array}{l}\mathrm{Fe}_{2} \mathrm{O}_{3}, \\
\text { wt } \%\end{array}$ & $\begin{array}{l}\mathrm{TiO}_{2} \text {, } \\
\text { wt } \%\end{array}$ & $\begin{array}{l}\mathrm{Na}_{2} \mathrm{O}, \\
\text { wt } \%\end{array}$ & $\begin{array}{l}\mathrm{K}_{2} \mathrm{O}, \\
\text { wt } \%\end{array}$ & $\begin{array}{l}\mathrm{SO}_{3}, \\
\mathrm{wt} \%\end{array}$ & $\begin{array}{l}\text { Loss in } \\
\text { ignition } \\
\text { for C, } \\
\text { wt } \%\end{array}$ \\
\hline Slag & 38.5 & 35.2 & 12.6 & 10.6 & 1.1 & 0.4 & - & - & 0.1 & 1.5 \\
\hline $\begin{array}{l}\text { Class } \\
\text { C fly } \\
\text { ash }\end{array}$ & 25.6 & 36.2 & 20.1 & 5.4 & 6.7 & - & 1.7 & 0.5 & 1.7 & 2.1 \\
\hline $\begin{array}{l}\text { Class } \\
\text { F fly } \\
\text { ash }\end{array}$ & 0.47 & 39.3 & 38.6 & 1.4 & 12.9 & - & 1.5 & 1.9 & 1.2 & 2.7 \\
\hline
\end{tabular}

Sodium carboxymethyl cellulose (CMC) under the production name "Walocel CRT 30 PA," supplied by Dow Chemical Corp., was used as the thermal degradable additive to 
promote the disintegration of the slag/fly ash-based sealers; it dissolves in water forming an anionic polymer. The CMC was produced by the etherification of cellulose from renewable resources, like wood, and had the chemical structure shown in Figure 1. We used it at $0.4,0.7,0.9,1.0,1.2$, and $1.5 \%$ by total weight of dry slag/fly ash mixture. Hard burned magnesium oxide ( $98.3 \mathrm{wt} \% \mathrm{MgO}$ ) under the trade name "MagChem 10 CR" from Martin Marietta Magnesia Specialties, LLC was used as expansive additive. Its physical properties included $97 \%$ passing 200 mesh $(0.074 \mathrm{~mm})$ and surface area ranging from 0.2 to $0.3 \mathrm{~m}^{2} / \mathrm{g}$. The contents of $\mathrm{MgO}$ additive were $0.5,1.0,1.5,2.0$, and $3.0 \%$ by the total weight of cement components.

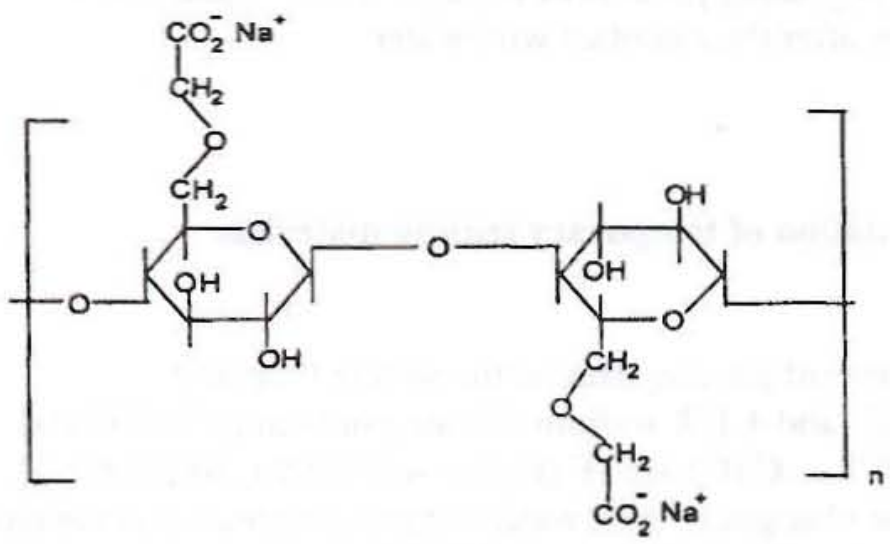

Figure 1. Chemical structure of CMC.

The sodium silicate alkali-activated slag/Class $\mathrm{C}$ and /F fly ash (AASC and AASF) slurries with CMC were prepared by adding an appropriate amount of water to the dry mix cementitious component, and then left them in an atmospheric environment until the cement set. Afterward, these room temperature-set AASC and AASF samples were exposed in an autoclave at $200^{\circ} \mathrm{C}$ for 5 hours under the hydrothermal pressure ranging from 300 to $1000 \mathrm{psi}$. Some autoclaved samples then were heated for 24 hours in oven at $200^{\circ}, 250^{\circ}$, and $300^{\circ} \mathrm{C}$. The commercial Class $\mathrm{G}$ well cement modified with $4.1 \%$ sodium silicate and $0.7 \% \mathrm{CMC}$ also was exposed to the same conditions as those of AASC and AASF samples.

\section{Measurements}

The initial- and final-setting times of the CMC-containing AASC and AASF sealing slurries at $85^{\circ} \mathrm{C}$ were determined in accordance with modified ASTM C 191-92 [31]. In it, a slurry-filled conical mold was placed in screw-topped round glass jar to avoid any evaporation of water from the slurry during heating. The slurry was examined every 30 minutes to determine its setting time. The porosity of autoclaved and heated CMCcontaining AASC and AASF was measured by helium pyconometry. Two specimens with size of $35 \mathrm{~mm}$ diameter $\times 35 \mathrm{~mm}$ length, and $35 \mathrm{~mm}$ diameter $\times 70 \mathrm{~mm}$ length were used for measuring porosity and determining compressive strength, respectively. Differential scanning calorimetry (DSC) and thermogravimetric analyzer (TGA) give us 
information on the thermal decomposition and decomposition kinetic of $\mathrm{CMC}$; further, we adapted Fourier transform infrared spectroscopy (FT-IR) to reveal the chemical behavior of the decomposed CMC in AACM. X-ray powder diffraction (XRD) and FTIR were used to identify the crystalline and amorphous hydrothermal reaction products of the autoclaved samples. The high-resolution scanning electron microscopy (HR-SEM) was employed to survey any alternations in the microstructure of sealers before and after its self-degradation, and also to explore the morphologies of the crystalline and amorphous hydrothermal reaction products formed in sealers. To identify these reaction products, we used energy-dispersible x-ray (EDX) concomitant with HR-SEM.

With a Type $\mathrm{K}$ thermometer, in conjunction with temperature data logger, we monitored the heat energy generated in a self-degrading process of the $200^{\circ}-, 250^{\circ}-$, and $300^{\circ} \mathrm{C}$ heated AASC and AASF specimens after their contact with water.

\section{Results and Discussion}

\section{Task 1. Establish the basic formulation of temporary sealing materials}

\subsection{Initial and final setting times}

Our first experiment was directed toward gaining data on the setting time and compressive strength of $0.7 \%$ CMC- and $4.1 \%$ sodium silicate-containing AASC and AASF samples made with slag (S)/Class $\mathrm{C}(\mathrm{C})$ and $/ \mathrm{F}(\mathrm{F})$ ratios of $100 / 0,80 / 20,60 / 40$, $40 / 60$, and $20 / 80$. Table 2 shows the changes in their water content, expressed as the ratio of water (w) to dry cement (c), as a function of the $\mathrm{S} / \mathrm{C}$ and /F ratio used in preparing the AASC and AASF slurries; it includes their initial- and final-setting times at $85^{\circ} \mathrm{C}$. The water content in these AASC and AASF systems was adjusted to attain a consistency similar to that of Class $\mathrm{G}$ well cement slurries made with the w/c ratio of 0.54 . As is evident, the w/c ratio decreased as some portion of slag was replaced by Class $\mathrm{C}$ and $\mathrm{F}$ fly ashes. For commercial Class $\mathrm{G}$ well cement, its initial setting time without CMC was $\sim 90 \mathrm{~min}$. After adding $0.7 \% \mathrm{CMC}$, there was no evidence of initial setting time within $360 \mathrm{~min}$. Undoubtedly, CMC retarded the setting of the Class G cement. In contrast, $\mathrm{CMC}$ was not as much as effective in retarding the setting of all AASC and AASF slurries, except for 20/80 slag/fly ash F ratio slurry; these slurries were set in curing periods up to $\sim 210 \mathrm{~min}$. However, the slurries made with three formulas related to $100 / 0$, $80 / 20$, and $60 / 40 \mathrm{~S} / \mathrm{C}$ ratios failed to meet the criterion $\geq 60 \mathrm{~min}$. Thus, no further test was conducted for these formulas.

Table 2. Water/cement ratio, and initial and final setting times at $85^{\circ} \mathrm{C}$ for slurries made with various slag/Class $C$ and $/ F$ fly ash ratios and Class $G$ well cement.

\begin{tabular}{|l|l|l|l|}
\hline Formula & $\begin{array}{l}\text { Water/cement, w/c } \\
\text { ratio }\end{array}$ & $\begin{array}{l}\text { Initial setting time at } \\
85^{\circ} \mathrm{C}, \text { min }\end{array}$ & $\begin{array}{l}\text { Final setting time at } \\
85^{\circ} \mathrm{C}, \text { min }\end{array}$ \\
\hline Class G well cement & 0.54 & $>360$ & Unknown \\
\hline $100 / 0$ S/C & 0.47 & $<30$ & $<60$ \\
\hline $80 / 20 \mathrm{~S} / \mathrm{C}$ & 0.46 & $<30$ & $<60$ \\
\hline $60 / 40 \mathrm{~S} / \mathrm{C}$ & 0.45 & $\sim 30$ & $\sim 60$ \\
\hline $40 / 60 \mathrm{~S} / \mathrm{C}$ & 0.45 & $\sim 60$ & $\sim 90$ \\
\hline
\end{tabular}




\begin{tabular}{|l|l|l|l|}
\hline $20 / 80 \mathrm{~S} / \mathrm{C}$ & 0.44 & $\sim 120$ & $\sim 180$ \\
\hline $80 / 20 \mathrm{~S} / \mathrm{F}$ & 0.45 & $\sim 60$ & $\sim 120$ \\
\hline $60 / 40 \mathrm{~S} / \mathrm{F}$ & 0.42 & $\sim 150$ & $\sim 270$ \\
\hline $40 / 60 \mathrm{~S} / \mathrm{F}$ & 0.40 & $\sim 210$ & $\sim 360$ \\
\hline $20 / 80 \mathrm{~S} / \mathrm{F}$ & 0.40 & $>210$ & Unknown \\
\hline
\end{tabular}

Furthermor, we surveyed the changes in initial and final setting times of cement as a function of CMC contents. Table 3 lists the water-to-cement (w/c) ratios and the initialand final-setting times at $85^{\circ} \mathrm{C}$ for Class G well cement and 20/80 S/C ratio AASC modified with $0.4,0.7$, and $1.0 \mathrm{wt} \% \mathrm{CMC}$. In both the cement systems, the w/c ratio increased with an increasing $\mathrm{CMC}$ content, from 0.39 at $0 \% \mathrm{CMC}$ to 0.62 at $1.0 \% \mathrm{CMC}$ for Class G cement, and from 0.31 at $0 \% \mathrm{CMC}$ to 0.52 at $1.0 \% \mathrm{CMC}$ for AASC. Adding the $\mathrm{CMC}$ to the Class $\mathrm{G}$ cement remarkably prolonged its setting time; in fact, the value of initial setting time without CMC was extended by nearly $210 \mathrm{~min}$ to $\sim 300 \mathrm{~min}$ after incorporating $0.4 \% \mathrm{CMC}$. Correspondingly, adding more than $0.4 \% \mathrm{CMC}$ considerably delayed the hydration of cement so there was no evidence of initial setting time within $360 \mathrm{~min}$. In contrast, all 20/80 S/C ratio AASC modified with CMC were set for curing period up to $\sim 210 \mathrm{~min}$. With $0.4 \% \mathrm{CMC}$, both the initial- and final-setting times of CMC-free AACM were prolonged by $\sim 30 \mathrm{~min}$ to $\sim 90$ and $\sim 120 \mathrm{~min}$. Further increasing amount to $0.7 \%$ led to the extension of another 30 and $60 \mathrm{~min}$ of initial- and final-setting times over that of $0.4 \%$. Nevertheless, at the room temperature of $\sim 25^{\circ} \mathrm{C}$, the final setting of both the Class G and AASC specimens was observed within 30 hours after mixing with water.

Table 3. Changes in water/cement ratio, and initial-and final-setting times of 20/80 S/C ratio AASC and Class $G$ well cement as a function of CMC content.

\begin{tabular}{|l|l|l|l|l|}
\hline & $\begin{array}{l}\text { CMC content, } \\
\text { wt\% }\end{array}$ & $\begin{array}{l}\text { Water/cement, } \\
\text { w/c, ratio }\end{array}$ & $\begin{array}{l}\text { Initial setting } \\
\text { time at } 85^{\circ} \mathrm{C}, \\
\text { min }\end{array}$ & $\begin{array}{l}\text { Final setting } \\
\text { time at } 85^{\circ} \mathrm{C}, \\
\text { min }\end{array}$ \\
\hline \multirow{2}{*}{$\begin{array}{l}\text { Class G well } \\
\text { cement }\end{array}$} & 0 & 0.39 & $\sim 90$ & $\sim 90$ \\
\cline { 2 - 5 } & 0.4 & 0.48 & $\sim 300$ & $>360$ \\
\cline { 2 - 5 } & 0.7 & 0.54 & $>360$ & \\
\cline { 2 - 5 } & 1.0 & 0.62 & $>360$ & \\
\hline \multirow{2}{*}{ AASC S/C ratio } & 0 & 0.31 & $\sim 60$ & $\sim 90$ \\
\cline { 2 - 5 } & 0.4 & 0.38 & $\sim 90$ & $\sim 120$ \\
\cline { 2 - 5 } & 0.7 & 0.44 & $\sim 120$ & $\sim 180$ \\
\cline { 2 - 5 } & 1.0 & 0.52 & $\sim 120$ & $\sim 210$ \\
\hline
\end{tabular}

\subsection{Sodium carboxymethyl cellulose (CMC) additive as self-degradation promoter} Two thermal analytical tools, DSC and TGA, were employed to study the thermal decomposition of $\mathrm{CMC}$ as a self-degradation promoter of sealers.

Figure 2 depicts the DSC curve of the $\mathrm{CMC}$ at temperatures from $100^{\circ}$ to $450^{\circ} \mathrm{C}$ in nitrogen; it encompasses two endothermic-transition peaks, $T_{p l}$ and $T_{p 2}$, at $270^{\circ}$ and $304^{\circ} \mathrm{C}$. Since these endothermic peaks reflect the thermal decomposition of the samples, 
CMC seemingly undergoes a two-stage decomposition process. The onset of the first stage began at $165^{\circ} \mathrm{C}$, denoted as $T_{01}$ and ended at $295^{\circ} \mathrm{C}$, marked as $T_{02}$. The second stage occurred at $295^{\circ}$ and ended at $322^{\circ} \mathrm{C}$ as $T_{e}$. To support this information, we determined the exothermic decomposition energy evolved on each stage of CMC's thermal decomposition from the closed areas of the curves with the baseline. The values for the first- and second-stages were 510.8 and $53.8 \mathrm{~J} / \mathrm{g}$, respectively, meaning that the most of CMC's decomposition took place at temperatures between $165^{\circ} \mathrm{C}$ and $295^{\circ} \mathrm{C}$.

In addition, we employed TGA to obtain information on the quantitative analysis and kinetic study of CMC's thermal decomposition (Figure 3). The TGA curve revealed that its decomposition began at $168^{\circ} \mathrm{C}$, which closely resembled to that obtained from DCS, and was completed at $303^{\circ} \mathrm{C}$. The total loss in weight of CMC occurring between $168^{\circ}$ and $303^{\circ} \mathrm{C}$ was $42.6 \%$, implying that a large volume of gaseous species was emitted during the decomposition of $\mathrm{CMC}$. The thermal decomposition kinetic computed by integrating the closed areas of curves with the baseline revealed that a half of CMC's total weight loss took place at temperatures from $168^{\circ}$ to $\sim 260^{\circ} \mathrm{C}$. Unlike DSC, TGA did not show any other weight loss related to its second stage of decomposition.

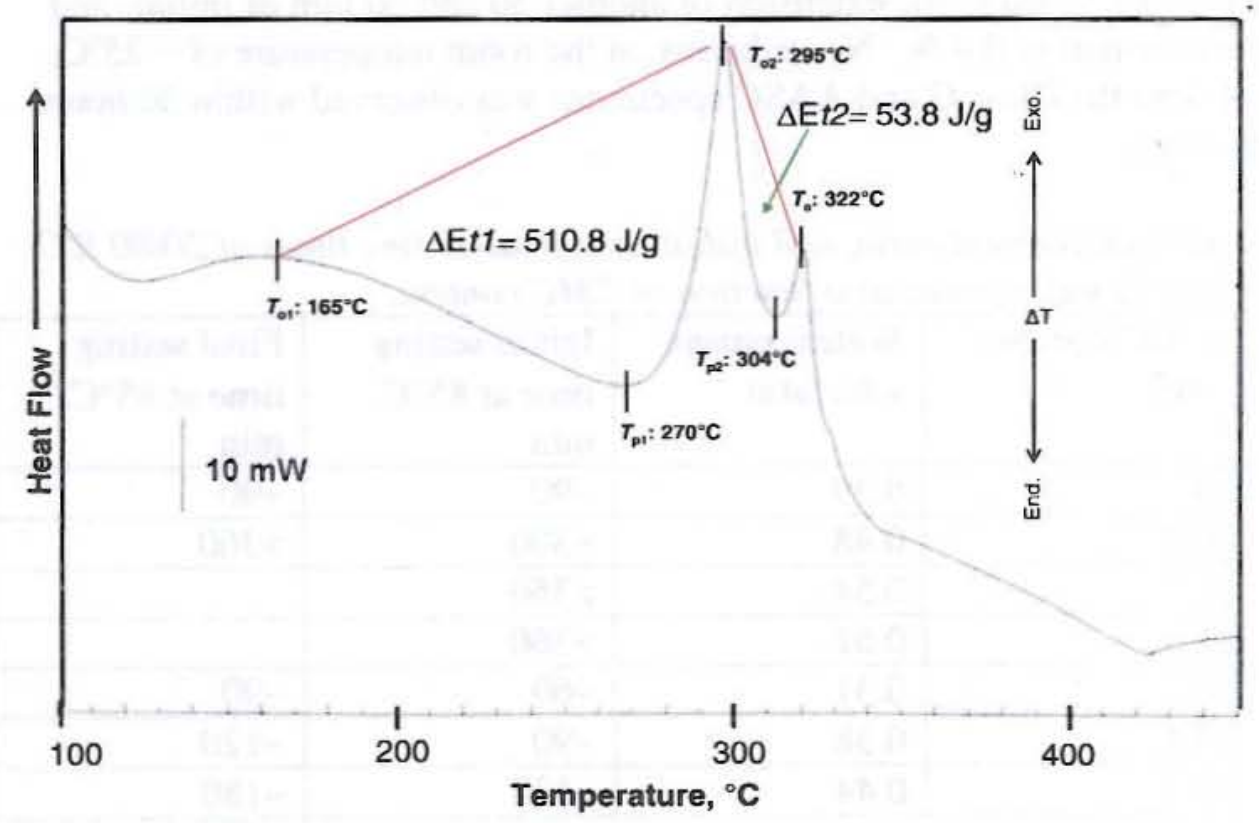

Figure 2. DSC curve of CMC. 


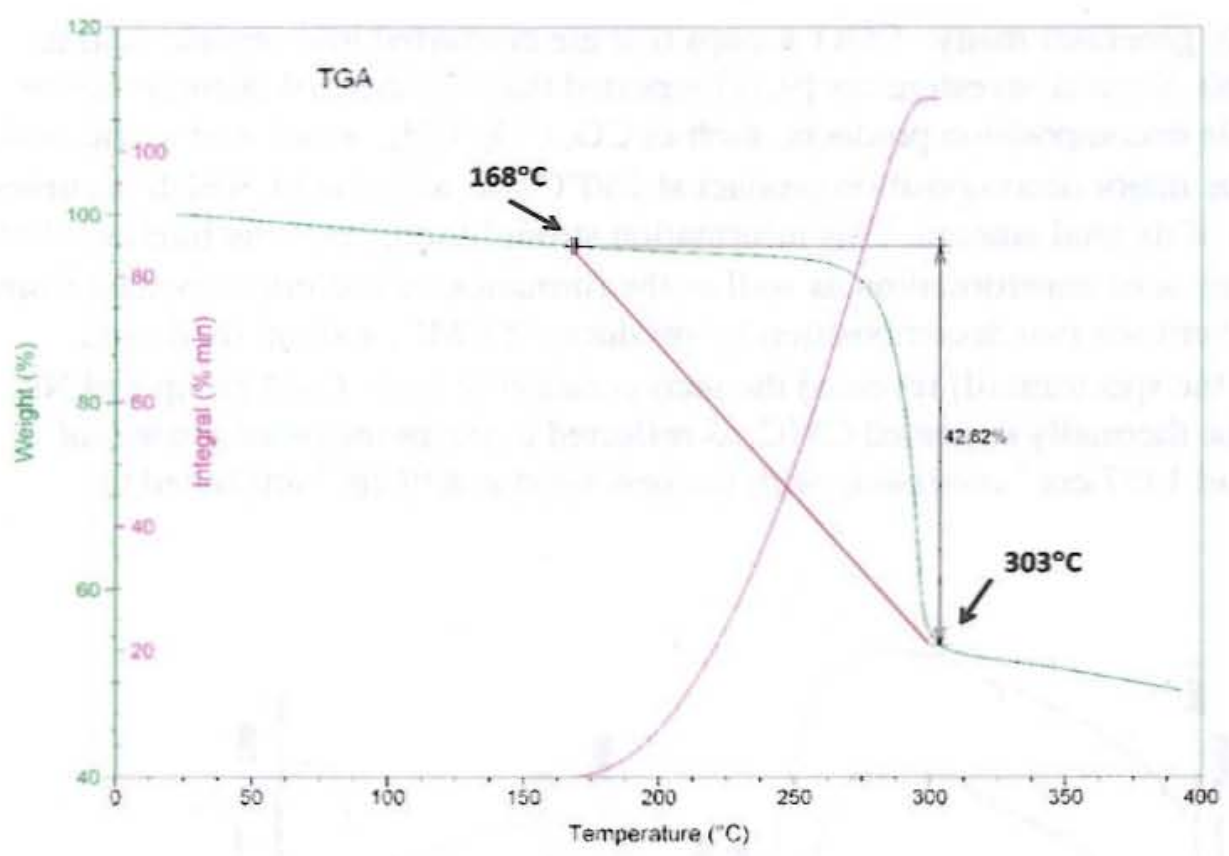

Figure 3. TGA curve of CMC.

Our study next shifted to clarifying the chemistry of CMC's thermal decomposition. To do so, FT-IR analyses in the wavenumber region, $3500-700 \mathrm{~cm}^{-1}$ were carried out for non-heated and heated $\mathrm{CMC}$ at $200^{\circ}, 250^{\circ}$, and $300^{\circ} \mathrm{C}$ for 24 hours (Figure 4). Based upon the chemical structure of CMC in Figure 1, in conjunction with literature survey [32-34], the spectrum (a) of the $80^{\circ} \mathrm{C}$-made CMC film included several prominent absorption bands at 2925 and $2864 \mathrm{~cm}^{-1}$ associated with C-H anti-symmetric and symmetric stretching vibrations, at $1603 \mathrm{~cm}^{-1}$ belonged to aromatic $\mathrm{C}=\mathrm{C}$ stretching mode, at $1576 \mathrm{~cm}^{-1}$ shoulder attributed to $\mathrm{C}-\mathrm{O}$ anti-symmetric stretching in the carboxylate ion group, $-\mathrm{COO}^{-}$, at $1400 \mathrm{~cm}^{-1}$ due to $-\mathrm{CH}_{2}$ scissoring overlapped with $\mathrm{C}-\mathrm{O}$ symmetric stretching in $-\mathrm{COO}^{-}$, at $1329 \mathrm{~cm}^{-1}$ related to both $-\mathrm{CH}_{2}$ scissoring and $\mathrm{C}-\mathrm{OH}$ bending, at $1157 \mathrm{~cm}^{-1}$ referred to $\mathrm{C}-\mathrm{O}-\mathrm{C}$ stretching in the ether group, and both at 1057 and 1020 $\mathrm{cm}^{-1}$ assignable to $\mathrm{C}-\mathrm{O}$ stretching in $>\mathrm{CH}-\mathrm{O}-\mathrm{CH}_{2}$ - linkage. Compared with this, FT-IR spectrum (b) of the $200^{\circ} \mathrm{C}$-heated CMC film was characterized by declining the band intensity at 1329,1057 , and $1020 \mathrm{~cm}^{-1}$, and disappearing the band at $1157 \mathrm{~cm}^{-1}$, demonstrating that heating the $\mathrm{CMC}$ at $200^{\circ} \mathrm{C}$ entailed the breakage and rupture of several linkages, such as $\mathrm{C}-\mathrm{OH}, \mathrm{C}-\mathrm{O}-\mathrm{C}$, and $>\mathrm{CH}-\mathrm{O}-\mathrm{CH}_{2-}$ within $\mathrm{CMC}$ 's molecular structure. Further increasing temperature to $250^{\circ} \mathrm{C}$ incorporated five new bands at 1685 , $1457,879,835$, and $780 \mathrm{~cm}^{-1}$ into the spectrum (c). The possible contributors to these new bands at 1685 and $1457 \mathrm{~cm}^{-1}$ were the carbonyl, $\mathrm{C}=\mathrm{O}$, in ketone species formed by intra-ring dehydration $[35,36]$ and a carbonated compound like sodium carbonate, $\mathrm{Na}_{2} \mathrm{CO}_{3}$ [37], respectively. The other new bands emerging in low wavernumber region < $900 \mathrm{~cm}^{-1}$ might be associated with the organic fragments yielded by thermal degradation of CMC. This spectrum also strongly represented that the band at $1576 \mathrm{~cm}^{-1}$ attributed to $-\mathrm{COO}^{-}$ionic group had become one of the major peaks, while the aromatic- and $>\mathrm{CH}-\mathrm{O}$ $\mathrm{CH}_{2}$ - linkage-related bands had vanished. Thus, the thermal decomposition of CMC at 
$250^{\circ} \mathrm{C}$ seemingly generates many $-\mathrm{COO}^{-}$groups that are converted into organic acid in an aqueous media. Several investigators $[9,11]$ reported that this thermal decomposition generated volatile decomposition products, such as $\mathrm{CO}, \mathrm{CO}_{2}, \mathrm{CH}_{4}$, water, and acetic acid. Among those, the major decomposition product at $250^{\circ} \mathrm{C}$ was acetic acid, which occupies more than $40 \%$ of its total amount. This information strongly supported the likelihood of $-\mathrm{COO}^{-} \rightarrow$ organic acid transformation as well as the formation of sodium carbonate from the interactions between two decomposition by-products of $\mathrm{CMC}$, sodium oxide and $\mathrm{CO}_{2}$. At $300^{\circ} \mathrm{C}$, the spectrum (d) revealed the incorporation of more $\mathrm{C}=\mathrm{O}$ group and $\mathrm{Na}$ carbonate into the thermally degraded $\mathrm{CMC}$, as reflected in the pronounced growth of bands at 1685 and $1457 \mathrm{~cm}^{-1}$ coexisting with the new band at $849 \mathrm{~cm}^{-1}$ attributed to carbonate.

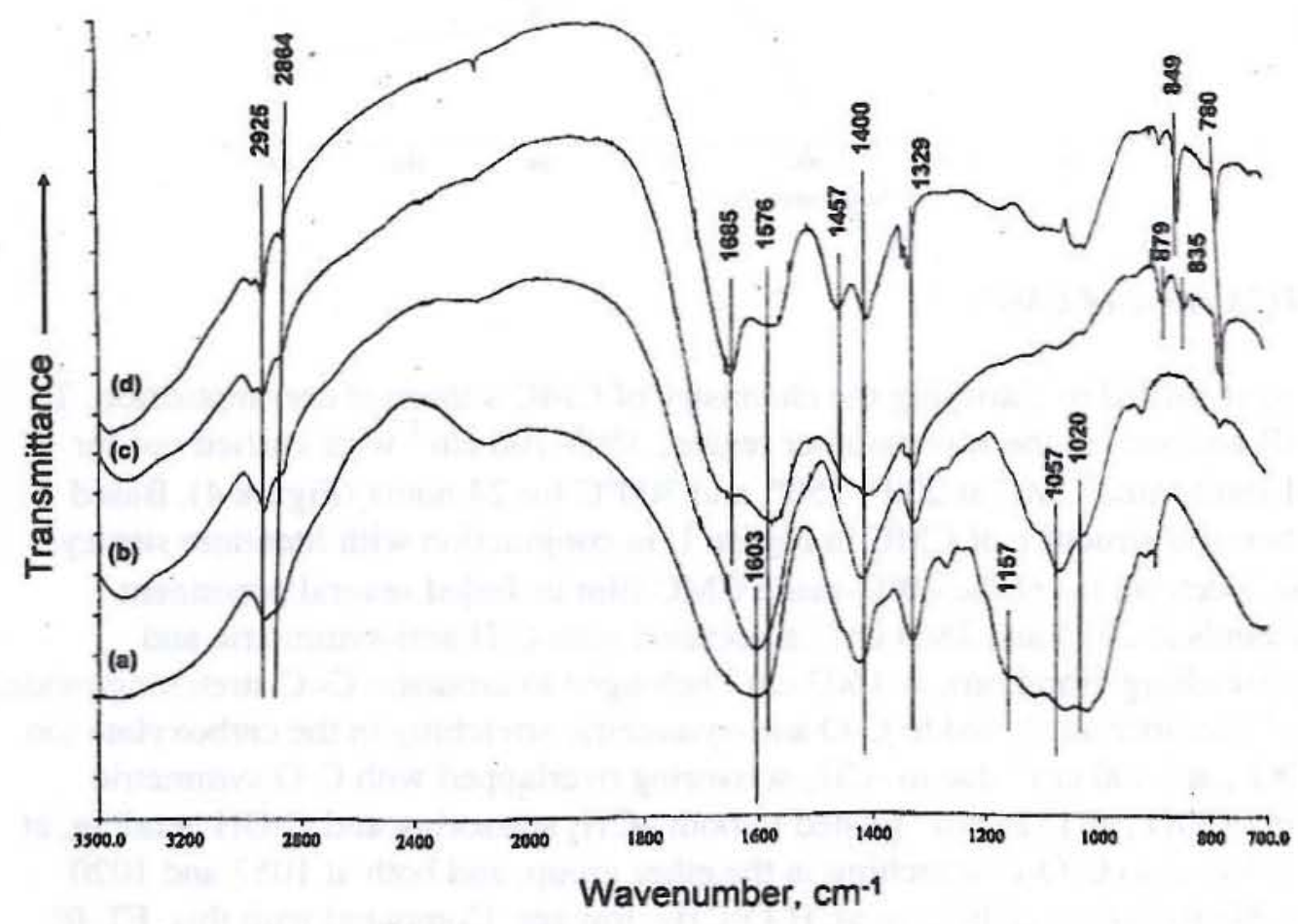

Figure 4. FT-IR spectra for $80^{\circ} \mathrm{C}$-made CMC film (a), and $200^{\circ} \mathrm{C}$ - (b), $250^{\circ} \mathrm{C}$-(c), and $300^{\circ} \mathrm{C}$-heated CMCs $(d)$.

\subsection{Thermal decomposition behaviors of CMC in AACM}

Based upon information described above, our focus next centered on investigating the thermal decomposition behaviors of CMC present in AACM. To elucidate them fully, we analyzed $1.0 \%$ CMC-modified 20/80 S/C ratio specimens by FT-IR. All specimens were dried in an oven at $85^{\circ} \mathrm{C}$ for 24 hours before analyzing them. The "as-received" slag and Class C fly ash were used as reference materials. Figure 5 illustrates the FT-IR spectra of these references; for slag, the spectrum had three prominent bands at $\sim 2923 \mathrm{~cm}^{-1}, \sim 1620$ $\mathrm{cm}^{-1}$, and $\sim 1430 \mathrm{~cm}^{-1}$, and one wide band in the range of 1050 to $820 \mathrm{~cm}^{-1}$. The first two bands are associated with water adsorbed into cementitious body, while the third band is due to the carbonated compounds. In contrast, no carbonation product was found in Class 
$\mathrm{C}$ fly ash. Figure 6 compares the spectral features of specimens made under the room temperature for 24 hours and under four different conditions. The spectrum (a) of the room temperature-cured specimen, followed by heating at $80^{\circ} \mathrm{C}$ displayed CMC-related bands at 1597,1405 , and $1354 \mathrm{~cm}^{-1}$ in conjunction with that from carbonates at 1450 $\mathrm{cm}^{-1}$, and from water at 2923,2853 , and $1627 \mathrm{~cm}^{-1}$. Similar spectral feature, except for the appearance of carbonate-related band at $1420 \mathrm{~cm}^{-1}$, was obtained from specimen autoclaved at $200^{\circ} \mathrm{C}$ for 5 hours (b), strongly suggesting that CMC didn't fully decompose during such a short-term exposure in hydrothermal environment. In comparison, the features of specimen (c) heated at $200^{\circ} \mathrm{C}$ for 24 hours was different; in

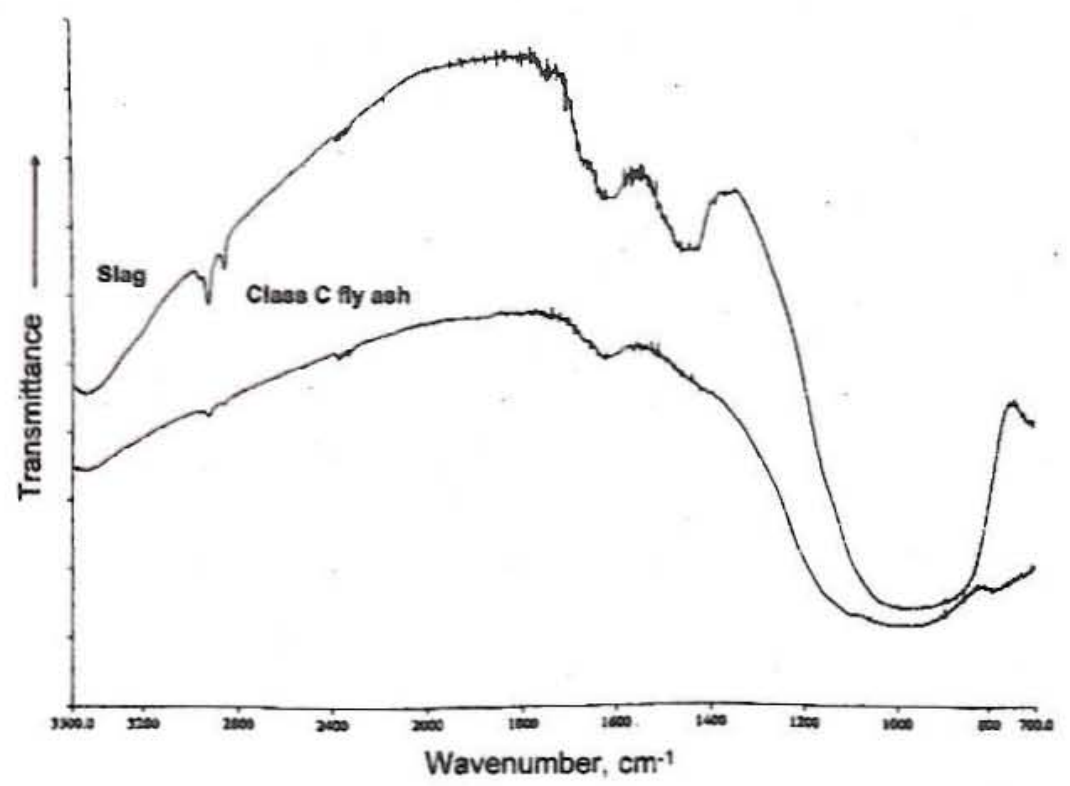

Figure 5. FT-IR spectra for slag and Class $C$ fly ash as references.

particular, all CMC-related bands were eliminated, but the band at $1420 \mathrm{~cm}^{-1}$ expressed marked growth. As discussed in the DSC and TGA studies of bulk CMC, the thermal degradation of $\mathrm{CMC}$ begun at $\sim 170^{\circ} \mathrm{C}$, subsequently, causing the emission of $\mathrm{CO}_{2}$. Hence, it is reasonable to consider that the in-situ dry carbonation reactions between the $\mathrm{CO}_{2}$ and alkaline earth metals, like the $\mathrm{Ca}$ from slag and Class $\mathrm{C}$ fly ash or alkaline metals like $\mathrm{Na}$ from $\mathrm{CMC}$ occurred in these cementitious bodies during heating, and lead to the formation of carbonation products, such as $\mathrm{CaCO}_{2}$ and $\mathrm{Na}_{2} \mathrm{CO}_{3}$. At $250^{\circ}$ (d) and $300^{\circ} \mathrm{C}$ (e), their spectral features closely resembled to that at $200^{\circ} \mathrm{C}$.

As a result, at $\geq 200^{\circ} \mathrm{C}$, the extent of thermal decomposition of CMC in AACM seemingly depended on the duration of exposure time; namely, a short-term autoclave treatment of specimens for 5 hours was not as efficacious in the generation of gaseous phase emitted by CMC's thermal decomposition as that of the 24-hour long heat-treated specimens at the same temperature. 
